\title{
A CLINICAL AND BACTERIOLOGICAL SURVEY OF PNEUMONIA IN CHILDHOOD
}

BY

\author{
ESTHER HENDRY, M.D., D.C.H.
}

(From the Department of Paediatrics, Glasgow University and the Royal Hospital for Sick Children, Glasgow)

Largely through the work of Cooper and her co-workers (1929), thirty-three fairly distinct types of pneumococci have been isolated. This subdivision, however, is not final. Types 6 and 26 are now understood to be identical, as also are types 15 and 30, whereas the Wilder strain, numbered type 33 is now thought to be related to type 9. In the light of Cooper's (1929) classification, workers on both sides of the Atlantic have studied the different types in health and disease. The strains most often encountered vary from country to country and even from district to district, and epidemics due to one particular strain of pneumococcus have been reported. Although it is generally agreed that certa in types are more usually isolated in disease than in health, those infesting the upper respiratory tract of normal subjects may also be pathogenic. This frequently occurs in respiratory disease in children, who have had little opportunity to develop immunity to organisms which may be regarded as innocuous inhabitants of the adult throat (Cooper, Rosenstein, Walter and Peizer, 1932; Nemir, Andrews and Vinograd, 1936).

The present investigation is based on a study of one hundred and eighty-six consecutive cases of pneumonia admitted to one of the medical units of the Royal Hospital for Sick Children, Glasgow, between October 1, 1939, and September 30, 1940. These cases have been reviewed with special reference to the course, complications, response to treatment and mortality rate in relation to the type of organism isolated from the throat or the nose, from purulent exudate and post-mortem specimens. Twenty-three cases suffering from conditions other than pneumonia from which the pneumococcus was recovered are also included. The ages of the children ranged from four days to twelve years.

\section{Investigation}

Methods. Throat, and sometimes also nasal swabs were taken from all the patients on admission, at intervals during their stay in hospital, and in a follow-up after discharge. In some instances cultures of pus from middle ear or pleura were also obtained to compare with the throat cultures, and, in fatal 
cases coming to autopsy, cultures from the lung, the spleen and bile, provided further material for investigation. The causal organism was identified by intraperitoneal injections of broth culture into mice and by using the resulting peritoneal exudate, or sometimes heart blood cultures, for typing with Lederle's series of immune sera. The criterion determining the specific type was capsule swelling (Neufeld reaction).

Clinical material. Of the one hundred and eighty-six cases, one hundred and eighty-two suffered from primary and four from secondary pneumonia. The diagnosis was based on clinical and radiographic findings and in a considerable number of the fatal cases confirmed by post-mortem examination. In one hundred and six (57 per cent.) of the one hundred and eighty-six cases a pneumococcus was recovered from the throat or elsewhere, either when the child was admitted or on subsequent attempts to isolate the organism. In the remaining eighty cases, streptococci, staphylococci, coliform bacilli or a mixture of these, were the only organisms found on repeated examination. The cases could thus be divided into two groups: (1) those infected with the pneumococcus, and (2) those infected with other organisms. This distinction will be maintained during discussion of the various points under review.

The incidence of pneumonia. Pneumonia is a disease of the winter and spring months. Finland (1937), in reviewing three thousand six hundred and eighty-two cases in Boston City Hospital, found that the greatest number occurred from January to March, while Bullowa (1937) states that December, January, February and March were his peak months. His 'type' incidence varied from month to month while Finland's (1937) remained constant throughout the year. According to Reimann (1938), pneumonia is of frequent occurrence in sparsely populated districts where the inhabitants, as is the case with young children, have had little chance to acquire immunity from repeated mild infections; he also considers that upper respiratory tract infection, by lowering the patient's resistance, predisposes to the disease. This lack of acquired immunity is probably the reason for the high incidence of pneumonia in children under two years of age (Bullowa, 1937; Finland, 1937) who are specially liable to become infected by one of the ' higher' types of pneumococci inhabiting a presumably healthy adult carrier's throat. Andrews (1937) has investigated a large series of cases in children for evidence of contact infection in the home and has come to the conclusion that, with certain types $(1,5,14$, $22,25,8,10$ and 17) more commonly encountered than others, the pneumonia was always due to the strain isolated from the child's throat, and that in infants and young children especially, familial infection was a frequent occurrence.

Fig. 1 shows the seasonal incidence of the cases in the present series. The continuous line indicates the total for each month, the interrupted line those cases which yielded a pneumococcus and the dotted line those from which some other organism was obtained on culture. The figure shows that there were epidemics of pneumonia in January, May and August. The unexpected rises in incidence in May and August were caused mainly by infection with type 19 pneumococcus. This organism accounted for $20 \cdot 8$ per cent. of all cases taking the year as a whole, for 30.9 per cent. of the cases occurring in May and for 40 per cent. of those occurring in August. It was only in these months that a single type of pneumococcus was responsible for a high proportion of the cases. There was nothing to suggest that these cases in May and August had any common source of infection or that bad housing, allowing infection to spread from adult carriers, was more frequently a predisposing factor at these times than at any others.

Age and sex incidence. Sixty-four (60.3 per cent.) of the children suffering from pneumococcal pneumonia were under two years of age while fifty-nine (73.7 per cent.) of the cases of non-pneumococcal pneumonia occurred in this 
To Show the Seasonal Incidence of Pneumonia.

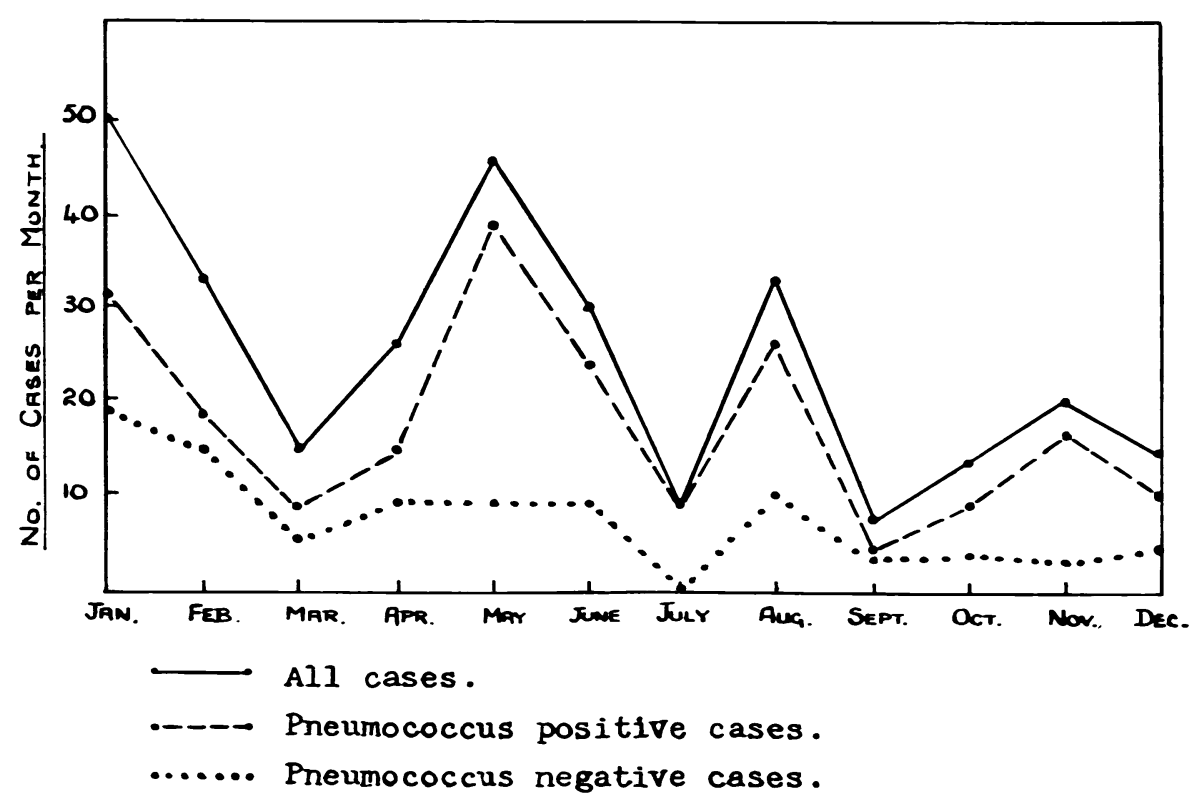

age group. These figures are in agreement with those of other workers. Sixtyfour were males and one hundred and twenty-two females, a ratio of $1: 2$. Bullowa's (1937) sex incidence, however, was 7 males to 3 females for both adults and children.

Housing conditions. In the series under review, bad housing conditions seemed to predispose to pneumococcus infection though no one type of pneumococcus was particularly responsible. Taking three persons or more per room as indicating over-crowding, it was found that sixty-five (61.3 per cent.) of the pneumococcus positive cases and twenty-nine (36 per cent.) of the pneumococcus negative came from over-crowded homes. This high incidence of infection with pneumococci among children living in over-crowded houses is probably due to close contact with adult carriers. No attempt was made, however, to substantiate this supposition by making cultures from the throats of adults in contact with the patients.

The course of the disease. With the exception of the relatively small number of cases which ended fatally, the disease generally ran a mild to moderately severe course for both groups of patients. In most, the onset was sudden with pyrexia ranging from 100 to $104^{\circ} \mathrm{F}$., but under treatment with sulphapyridine, which was given as a routine to all patients, this dropped to normal in the course of three or four days. It was customary to continue administration of the drug for three to four days after the temperature had subsided and the pulse and respiration rates had returned to normal. The period during which the drug was given has been regarded as the duration of the acute stage of the illness. This for pneumococcus positive cases averaged 8.75 days and 7.6 days for those infected with other organisms.

The white cell counts, which may be taken as a measure of the patient's reaction to the invading organism, were surprisingly low and there was no 
evidence that any one type of pneumococcus evoked a particular response. The average count was 17,273 white blood cells per c.mm.; the highest being 45,600 , with a type 19 infection, and the lowest 8,400 per c.mm. with type 6 . The highest count met with amongst the cases of empyema was only 22,800 . As only the counts registered on admission have been taken into consideration, the question of agranulocytosis following administration of sulphapyridine does not arise. For the non-pneumococcal groups, the average white cell count was slightly lower at 14,200 per c.mm. The maximum was 34,000 and the minimum 6,000 per c.mm.

An uncomplicated recovery was the rule and occurred in ninety ( 85 per cent.) of the group 1 cases and seventy-two ( 90 per cent.) of the group 2 . cases. Second attacks of pneumonia within a year of the first attack were recorded in 5 per cent. of the children in the first group and in 6.1 per cent. of those in the second group.

Complications. In both groups 1 and 2 , otitis media was the complication most frequently encountered. It occurred in seven cases in group 1 and in eight in group 2. In the seven cases of group 1 the types of pneumococcus found were types $6,22,23$, in two cases, 24 and 29 and in one case a mixed infection with types 20 and 31 . All the seven cases in group 1 died and two of those in group 2.

Empyema occurred in six patients with pneumococcus pneumonia, but in none of the cases with other infections. In three cases type 1 was the infecting organism; in two it was type 6 and in one type 11 . The last was the only case which died. Two children suffering from type 1 empyema made a slow recovery; the elder of these, a boy of eight years, had contracted a type 1 empyema for the second time in four years. In all, save the child who died, complete recovery ultimately took place.

Three cases developed meningitis. The infecting organisms were types 6 , 19 and 25 respectively. Two of these children were under one year of age, both came from poor and over-crowded homes and were acutely ill when admitted to hospital. The causal pneumococcus was isolated from the throat swab in each case. The patients offered no resistance to the infection and showed a poor response to treatment with sulphapyridine. Meningitis developed on the seventh day after admission in the child with type 6 infection and on the fourteenth day in the type 19 infection. In the third case, a type 25 organism was isolated from the cerebrospinal fluid during life, and at autopsy from splenic tissue and from the lung which showed broncho-pneumonic consolidation.

In the only case developing peritonitis, it was impossible to determine the type of infecting organism. The child, aged one year and three months, was admitted with bronchopneumonia, and during the first two weeks in hospital pneumococci, types 3 and 14, were repeatedly isolated alone and as a 'double' infection from throat swabs. The child failed to make any progress and developed peritonitis the day before death, four weeks after admission. As post-mortem examination was refused, peritoneal exudate was unobtainable for culture.

Arthritis occurred in one case of type 23 pneumonia. The child, aged nine weeks, at first seemed to do well on sulphapyridine, but after three weeks a relapse occurred, chest signs again appeared and swelling of the right knee was noted. Culture from a throat swab and from the fluid aspirated from the joint yielded type 23 pneumococcus. After a second course of sulphapyridine both lung and joint lesions healed satisfactorily and the child was discharged well.

Mortality. Nemir, Andrews and Vinograd (1936) are of the opinion that the mortality rate in pneumonia in childhood is dependent on age, type of infecting pneumococcus, pathological type of pneumonia (whether croupous 
or catarrhal) or a combination of these factors. Their death rate was 18 per cent. and they found that fatal results occurred most often in children under two years of age and in infections with types 1 and 4 pneumococcus. Reimann (1938) records a death rate of 15 per cent. for children under two years of age and makes special mention of the virulence of type 5 infections. In children over two years of age the death rate was 5 to 6 per cent. Bullowa's (1937) figures for the two age groups are 18.8 per cent. for the 'under twos' and 3.7 per cent. for the 'over twos.' Sulphapyridine was not used in the treatment of any of these cases.

In the present series there were twenty-five deaths, giving a death rate of 13.5 per cent. In the cases under two years of age with pneumococcal infection there were fifteen deaths ( 23 per cent.) and in those over that age two deaths ( 5 per cent.). Among the cases in the non-pneumococcal group there were eight deaths ( 14 per cent.) in the children under two years and none in those over that age. Taking both bacteriological groups together the mortality rate under two years was 19 per cent. and over two years 3 per cent. (see table 1).

TABLE 1

\section{MORTALITY}

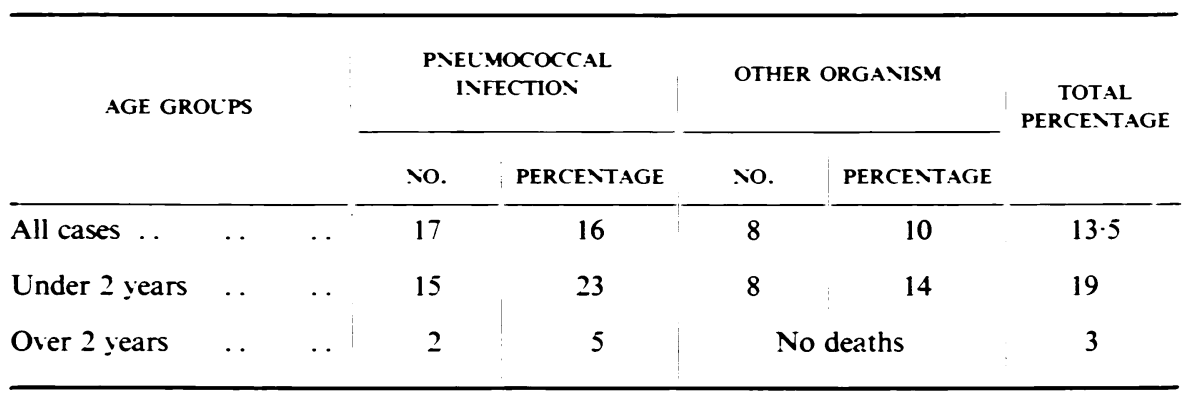

From table 2 it will be seen that no particular type of pneumococcus was responsible for a majority of the seventeen fatal cases in group 1.

Summarizing these results it appears that pneumonia caused by any of the types of pneumococcus is more serious than that caused by other organisms. These figures show a striking improvement in the mortality rates compared with figures taken from similar material in the same hospital for the years 1928 to 1932. Fleming (1933) records that the death rates at that time were 45 per cent. for children under three years of age and 6 per cent. for those over three years of age. This improvement seems to have taken place since the routine use of sulphapyridine was instituted. This was started in 1938 and in that year the death rate for children under two years of age was the same as that found for the present series (19 per cent.). In other respects the treatment of the 1928 to 1932 cases was carried out on similar lines to that employed since 1938 . Whether the improvement in mortality is entirely due to sulphapyridine treatment, it is impossible to say. Other factors, such as diminution in the virulence of the infection, may have played a part. It also appears that sulphapyridine is equally effective whether pneumonia is caused by the pneumococcus or by other organisms.

After results. After discharge from hospital the children were re-examined at fortnightly, monthly or three-monthly intervals (according to the severity of the illness). Recovery was complete in all cases, but in three (type 1, type 6 and type 22 pneumonias) resolution was slow though the child's general condition improved rapidly. With few exceptions, the causal pneumococcus 
disappeared from the child's throat soon after the acute stage of the illness was passed. Five children still harboured the organism up to two months after complete recovery. Two of these had type 6 and three type 19 infections - the two types most frequently encountered in the present series and those universally regarded as being of frequent occurrence in the carrier state.

TABLE 2

TO SHOW THE TYPES OF PNEUMOCOCCI ISOLATED FROM THE SEVENTEEN FATAL CASES IN GROUP 1

\begin{tabular}{|c|c|c|c|c|c|c|c|c|c|c|c|c|c|c|c|c|c|c|}
\hline \multirow{2}{*}{ DISEASE } & \multicolumn{18}{|c|}{ TYPE OF PNELMOCOCCUS } \\
\hline & 3 & 6 & 8 & 9 & 11 & 12 & 14 & 18 & 19 & 20 & 22 & 23 & 24 & 25 & 27 & 29 & 31 & TOTAL \\
\hline $\begin{array}{l}\text { Pneumonia } \\
\text { complicated) }\end{array}$ & & & $1 *$ & & 1 & 1 & & 1 & & $1 *$ & & & & & 1 & & & 5 \\
\hline $\begin{array}{cc}\text { Pneumonia } & \text { and } \\
\text { otitis media } & \ldots\end{array}$ & & 2 & & & & & & & & & 1 & 2 & 1 & & & 1 & & 7 \\
\hline $\begin{array}{cr}\text { Pneumonia } & \text { and } \\
\text { meningitis } & \ldots\end{array}$ & & & & 1 & & & & & & & & & & 1 & & & & 2 \\
\hline $\begin{array}{l}\text { Pneumonia, menin- } \\
\text { gitis and } \\
\text { media } \ldots \\
\text {.. }\end{array}$ & & & & & & & & & 1 & & & & & & & & & 1 \\
\hline $\begin{array}{rr}\text { Pneumonia } & \text { and } \\
\text { peritonitis } & \ldots\end{array}$ & $1 \div$ & & & & & & $1 \dagger$ & & & & & & & & & & & 1 \\
\hline $\begin{array}{r}\text { Pneumonia and } \\
\text { empyema (T.11) } \\
\text { and otitis media } \\
\text { (T.20 and } 31) \quad . .\end{array}$ & & & & & $1 \div$ & & & & & $1 \div$ & & & ? & & 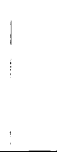 & & $1 \div$ & 1 \\
\hline
\end{tabular}

Incidence of pneumococcal types in pneumonia. One interesting fact which emerges from the study of pneumococcal infections in the child is the frequency with which certain strains encountered in health are also found in disease (Cooper, Rosenstein, Walter and Peizer, 1932). This is in marked contrast to the findings in the adult where the strains (usually types 1 and 2) regarded as responsible for the production of disease in a majority of cases are not often isolated from healthy 'carrier' throats. All workers are agreed that the ' higher' types of pneumococci are often responsible for the pneumonias of childhood and that type-incidence is different in children under three years of age from that in those over that age.

Table 3 shows the types other workers have found to be most prevalent in the pneumonias of childhood. From it one may conclude that pneumococci, types $1,6,14$ and 19, are the most usual organisms to be met with. Table 4 subdivides the results into the two age groups (under and over three years) and shows that type 14 is the organism most commonly found in children under three years of age and type 1 in children over that age. It should be noted that most of these results come from American sources. 
TABLE 3

INCIDENCE OF PNEUMOCOCCAL TYPES: REPORTS OF OTHER WORKERS ALL AGE GROUPS

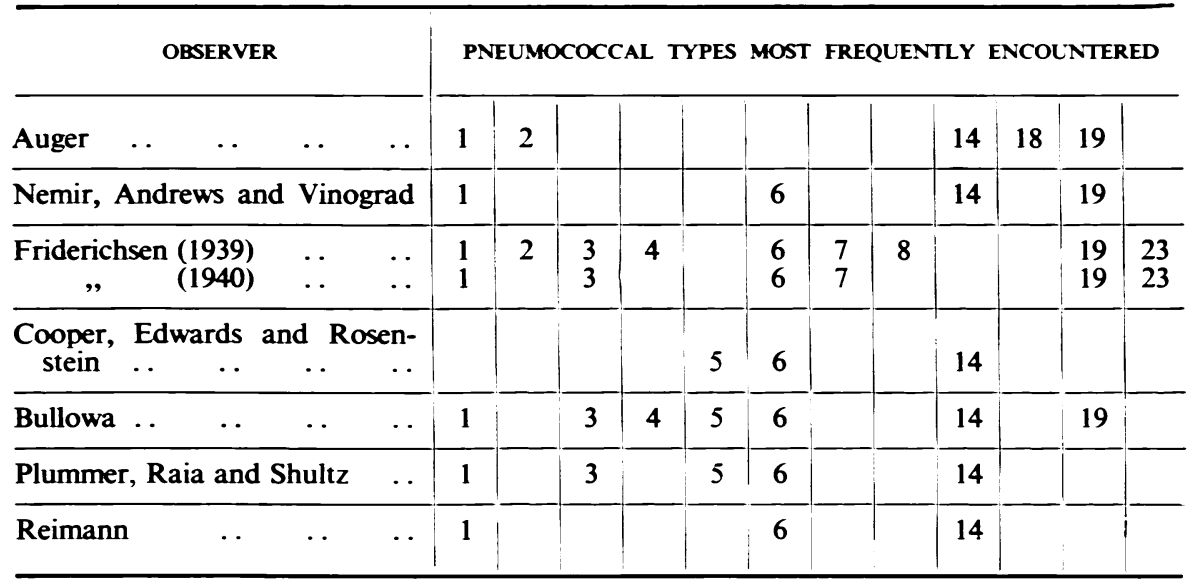

Fig. 2 shows the incidence of the different types of pneumococci isolated from the present series of one hundred and five cases of pneumococcus pneumonia and from twenty-three miscellaneous cases who did not have pneumonia, but from whom pneumococci were recovered from the upper respiratory tract or from some other part of the body. In all, two hundred and sixteen strains were recovered. It will be seen that types 6 (18.5 per cent.) and 19 (22 per cent.) were undoubtedly those most commonly encountered; together they accounted for 38.3 per cent. of all cases. The incidence of the various types in the present series corresponds closely with that found by Dr. K. J. Guthrie working in the same hospital and using the same methods in the investigation of a similar group of cases. Type 19, however, occurred almost twice as frequently in the present series as it did in Dr. Guthrie's. Type 14, cited as being of frequent occurrence by all American observers, is rare in either of the Glasgow series. In the present series, after types 6 and 19, types 1, 9, 11, 22, 23 and 29 in this order were the strains most often isolated. Types 28 and 32 were not met with.

No significant fact emerges from the correlation of pneumococcus types with age incidence. The types formerly included in group 4 were found scattered thr Jugh all age groups and the 'higher' types were not confined to infants and young children. Type 1 infection occurred much more frequently in children over two years than in those under that age. The type 1 pneumococcus was recovered from only two children under two years and from eight older children. The only type 2 pneumococcus encountered was isolated from the throat of a child aged fourteen weeks. Type 6 was found in seventeen children under two as compared with nine over two years of age and type 19 in fifteen of the older and eighteen of the younger age groups.

Incidence of pneumococeal types in miscellaneous cases. In this group of twenty-three cases there was no evidence of pneumonia. Table 4 shows the primary disease and the various pneumococcal types isolated. Only a few of these cases are worthy of special mention.

Of the two cases of meningitis the first occurred in a child of five years who was admitted to hospital with nephritis. She had had three previous attacks of pneumonia. Two weeks after admission she developed signs of meningitis and on lumbar puncture the cerebrospinal fluid yielded a growth of type 9 pneumococcus. She died four days later. Pneumococci were not isolated 
from throat or nasal swabs. At post-mortem examination atelectasis was discovered in the left lung. tenacious non-purulent material in the bronchi. acute nephritis and meningitis. Culture of bronchial secretion and splenic tissue produced no bacterial growth. The other case of meningitis was caused

\section{FIGURE 2.}

\section{To Show the Incidence of Types of Pneumococci.}

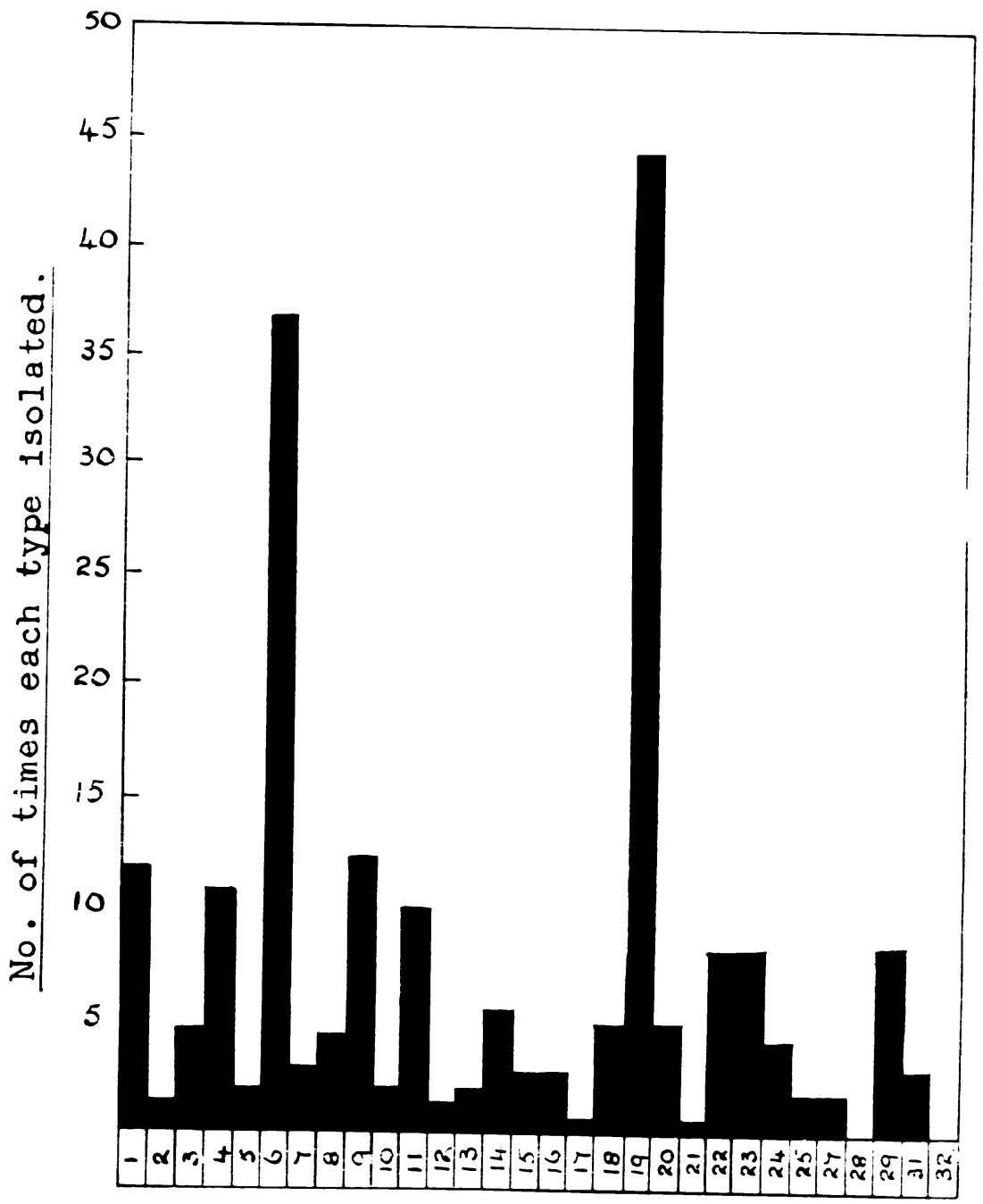

Type of Pneumococcus.

by type 18 pneumococcus. The child was one year and four months old and showed no signs of lung involvement. The organism was cultured direct from the cerebrospinal fluid. No post-mortem examination was made. Treatment with sulphapyridine did not seem to influence the course of the disease. 
TABLE 4

INCIDENCE OF PNEUMOCOCCAL TYPES UNDER AND OVER THREE YEARS OF AGE

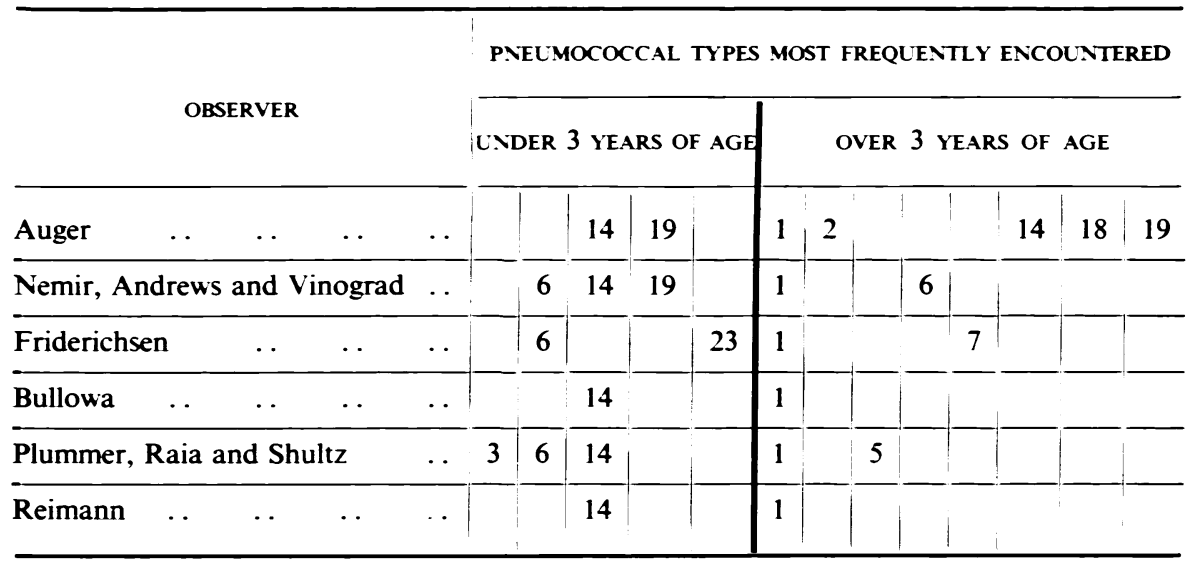

Of the two cases of arthritis one, a girl aged two years, with type 6 infection of the left ankle joint, also yielded the same organism from throat and nasal swabs, but there were neither clinical nor radiological signs of pneumonia. The other, an infant of four months suffered from a type 9 infection of an elbow joint. She made a good recovery after treatment with sulphapyridine without at any time showing signs or symptoms of a respiratory lesion or any evidence of the presence of a pneumococcus in the throat swab.

The case of conjunctival infection occurred in a four-day old infant. The infecting organism was a type 6 pneumococcus. A coliform bacillus was isolated from the culture of the throat swab.

TABLE 5

TO SHOW THE TYPE INCIDENCE IN THE MISCELLANEOUS GROUP OF CASES (PRESENT SERIES)

\begin{tabular}{|c|c|c|c|c|}
\hline \multicolumn{3}{|c|}{ DISE.ASE } & \multirow{2}{*}{$\begin{array}{c}\begin{array}{c}\text { NO. OF } \\
\text { CASES }\end{array} \\
5\end{array}$} & \multirow[b]{2}{*}{ Types $1,8,14,20$ and 8 and 20 together } \\
\hline Bronchitis & $\ldots$ & $\cdots$ & & \\
\hline Meningitis & .. & $\ldots$ & 2 & Types 6,18 \\
\hline Arthritis & . & $\ldots$ & 2 & Types 6,9 \\
\hline Tonsillitis & . & . & 8 & $\begin{array}{l}\text { Types } 3,6,15,19 \text { (twice) and } 8 \text { and } 14,3 \text { and } 4,15 \\
\text { and } 19 \text { together }\end{array}$ \\
\hline Conjunctivitis & . & $\cdots$ & 1 & Type 6 \\
\hline Bronchiectasis & .. & $\ldots$ & 1 & Type 19 \\
\hline Otitis media & .. & $\ldots$ & 2 & Types 21 and 24 \\
\hline Peritonitis & .. & .. & 1 & Type 1 \\
\hline
\end{tabular}

\section{Discussion}

The present investigation shows that pneumonia in childhood may be caused by almost any of the recognized types of pneumococcus. This is in agreement with the results of other workers. In the present series all the types, save 28 and 32, were shown to be responsible for the disease on one or more 
occasions. Type 33 was not tested for as the specific immune serum was not available. Type 19, a type which others have not found to be a usual cause of the disease, was the organism most often encountered. This is probably due to the large number of infections caused by it in May and August. Next in order of frequency came type 6, an organism that other workers have also frequently isolated. Types 1 and 2 were only rarely found in children under two years of age.

In the majority of the cases the course of the illness was remarkably similar, though physical signs varied from case to case; in some they showed a lobar and in others a lobular distribution. No evidence, either from clinical or radiological examination, could be obtained to suggest that a particular type of illness with distinctive signs and symptoms was caused by any one strain of pneumococcus. No single type of pneumococcus seemed to be specially responsible for any one of the complications met with, except possibly empyema in which three of the six cases were infected with the type 1 organism.

The response to treatment with sulphapyridine may be considered satisfactory, and it is difficult to avoid the conclusion that the great reduction in the mortality is attributable to the use of the drug. It must be remembered, however, that the virulence of infecting organisms varies from time to time. Though the present series of cases was comparable in every way to that studied in the same hospital in the years 1928 to 1932 it is possible that in the period during which sulphapyridine was employed, the disease had assumed a milder form. The fact that in children the disease may be caused by almost any of the known types of pneumococcus against all of which sulphapyridine is effective gives this drug a greater practical value in treatment than serum, for the usc of which special laboratory facilities are necessary.

\section{Summary}

1. One hundred and eighty-six cases of pneumonia have been investigated. One hundred and twenty-three or 66.4 per cent. of these occurred in children under two years of age.

2. The mortality rate was low. For children under two years it was 19 per cent. and for those over two years 3 per cent. Probably treatment with sulphapyridine was responsible for the low rate.

3. All the recognized types of pneumococci, save types 28,32 and 33 , were found on one or more occasions. Types 19 and 6 were the strains most frequently encountered. They accounted for $38 \cdot 3$ per cent. of the cases of pneumonia from which a pneumococcus was isolated.

4. Types 1 and 2 only occurred rarely in children under two years of age. Of the two types most frequently found (types 6 and 19) the former was evenly distributed between children under and over two years of age; the latter was relatively more frequently found in children over two years of age.

5. It was rare to find the causal pneumococcus persisting in the respiratory tract after the acute stage of the illness was over. 


\section{A CLINICAL SURVEY OF PNEUMONIA IN CHILDHOOD 121}

Thanks are due to Professor G. B. Fleming, to Dr. K. J. Guthrie of the Pathology Department, and to the clinical staff of the Hospital for much valuable help. Part of the expenses of the work was defrayed by a grant from the Medical Research Council. The sera for determining the pneumococcal types were kindly supplied by Messrs. Chas. F. Thackray, Ltd. The work was done during the tenure of a McCunn Scholarship.

\section{REFERENCES}

Andrews, E. T. (1937). Amer. J. Dis. Child., 54, 1285.

Auger, W. J. (1939). J. Pediat., 15, 646.

Bullowa, J. G. M. (1937). The management of the pneumonias, Oxford Med. Publications.

Cooper, G., Edwards, M., and Rosenstein, C. (1929). J. exp. Med., 49, 461.

Cooper, G., Rosenstein, C., Walter, A., and Peizer, L. (1932). Ibid., 55, 531.

Finland, M. (1937). Ann. intern. Med., 10, 1531.

Fleming, G. B. (1933). Glasg. med. J., 1 (N.S.), 56.

Friderichsen, C. (1939). Acta Paediatr., Stockh., 24, 165. (1940). Ibid., 27, 1.

Gundel, M., and Okura, G. (1933). Z. Hyg. Infektkr., 114, 678.

Gundel, M., and Seitz, L. (1933). Klin. Wschr., 12, 929.

Guthrie, K. J. Personal communication.

Nemir, R. L., Andrews, E. T., and Vinograd, J. (1936). Amer. J. Dis. Child., 51, 1277.

Plummer, N., Raia, A., and Shultz, S. (1931). Ibid., 40, 557.

Reimann, H. A. (1938). The pneumonias, Philadelphia and London.

Walter, A. W. (1938). Amer. J. publ. Hlth., 28, 54. 